\title{
Effects of Cationic Surfactants with an Alkyl Group of Different Chain Lengths on Permeability across Polymer Membranes Having Poly(L-glutamic acid) Domains
}

\author{
Dae-won Chung, Kenzo TanaKa, Mizuo MaEda, ${ }^{\dagger}$ \\ and Shohei INOUE* \\ Department of Synthetic Chemistry, Faculty of Engineering, \\ University of Tokyo, Hongo, Bunkyo-ku, Tokyo 113, Japan
}

(Received June 3, 1988)

\begin{abstract}
Effects of five cationic surfactants, decyl $\left(\mathrm{C}_{10}\right)$, dodecyl $\left(\mathrm{C}_{12}\right)$, tetradecyl $\left(\mathrm{C}_{14}\right)$, hexadecyl $\left(\mathrm{C}_{16}\right)$, and octadecyl $\left(\mathrm{C}_{18}\right)$ trimethylammonium chlorides, were investigated on the conformation of poly(L-glutamic acid) (PLGA) in a membrane composed of poly(butyl methacrylate)-poly(L-glutamic acid) graft copolymer, and on the permeability of phenyl-1,2ethanediol across the membrane. For the membrane treated with $\mathrm{NaOH}, \mathrm{C}_{10}, \mathrm{C}_{12}$, and $\mathrm{C}_{14}$ induced the coil-to-helix transition, but not $\mathrm{C}_{16}$ and $\mathrm{C}_{18}$. On the contrary, for the membrane treated with $\mathrm{HCl}, \mathrm{C}_{16}$, and $\mathrm{C}_{18}$ induced the helix-to-coil transition of PLGA, but not $\mathrm{C}_{10}, \mathrm{C}_{12}$, and $\mathrm{C}_{14}$. In most cases, treatment of the membrane with surfactants brought about decrease in the permeability of phenyl-1,2-ethanediol, except for the effect of $\mathrm{C}_{16}$ and $\mathrm{C}_{18}$ to enhance the permeability across the membrane pretreated with $\mathrm{HCl}$. These effects are considered due to increase in the hydrophobicity of the permeating pathway composed of PLGA chains, and/or their conformational transition in the membrane.

KEY WORDS Membrane / Permeability / Graft Copolymer / Poly(Lglutamic acid) / Conformational Transition / Cationic Surfactant /
\end{abstract}

Considerable attention has been focused on the conformational transition of poly(amino acid) in surfactant solutions, in connection with the effects of surfactant on the structure of proteins. Since the coil-to- $\beta$ transition of poly(L-lysine) was found to be induced by sodium dodecyl sulfate, ${ }^{1}$ extensive studies have been carried out on the interaction of poly(amino acid) with a surfactant. A general effect of ionic surfactants is to promote the formation of an ordered structure in poly(amino acid) with the opposite charge. ${ }^{2}$ For example, circular dichroism (CD) spectra of ionized poly(L-glutamic acid) (PLGA) at neutral $\mathrm{pH}$ showed that the conformation of PLGA changes from random coil to $\alpha$-helix by the addition of decylammonium chloride ${ }^{3}$ and dodecyltrimethylammonium chloride. ${ }^{4}$ On the other hand, the $\alpha$-helical form of PLGA at pH 4.5 changes to a random coil in the presence of hexadecyltrimethylammonium chloride. ${ }^{4}$

Recently, we prepared a polymer membrane composed of poly(butyl methacrylate)-poly(Lglutamic acid) graft copolymer (PBMA-gPLGA) (I, R=H) ${ }^{5,6}$ The membrane has hydrophilic PLGA domains functioning as permeating pathway for ionic and non-ionic solutes. PLGA segments in the membrane show-

\footnotetext{
${ }^{\dagger}$ Present address: Department of Organic Synthesis, Faculty of Engineering, Kyushu University, Hakozaki, Higashi-
} ku, Fukuoka 812, Japan.

* To whom all correspondence should be addressed. 
ed reversible conformational change induced by $\mathrm{pH}^{6}$ and urea. ${ }^{7}$ This conformational change influences the permeability of the solutes. The permselectivity of sugars could be regulated by the $\mathrm{pH}$-induced conformational change of PLGA chains. ${ }^{9}$

Cationic surfactants with a dodecyl group in common such as dodecylammonium chloride, dodecyldimethylammonium chloride and dodecyltrimethylammonium chloride brought about decrease in the permeability of phenyl1,2-ethanediol across a membrane composed of PBMA- $g$-PLGA, which is considered mainly due to the coil-to-helix transition of PLGA induced by these surfactants. ${ }^{8}$ In the present paper are described the effects of cationic surfactants with one alkyl group of different chain lengths on the conformation of PLGA in the membrane composed of PBMA- $g$-PLGA and on the permeability of phenyl-1,2ethanediol across the membrane. Surfactants examined are alkyltrimethylammonium chlorides, whose alkyl chain is decyl $\left(\mathrm{C}_{10}\right)$, dodecyl $\left(C_{12}\right)$, tetradecyl $\left(C_{14}\right)$, hexadecyl $\left(C_{16}\right)$, and the octadecyl $\left(\mathrm{C}_{18}\right)$ group.

\section{EXPERIMENTAL}

\section{Materials}

Poly(butyl methacrylate)-poly( $\gamma$-benzyl Lglutamate) graft copolymer (I, $\mathrm{R}=\mathrm{CH}_{2} \mathrm{C}_{6} \mathrm{H}_{5}$ ) was synthesized as described in our previous paper. ${ }^{6}$ The degree of branching $(x)$ and average degree of polymerization of the branches (y) of the graft copolymer were determined by ${ }^{1} \mathrm{H}$-NMR. ${ }^{7}$ The surfactants $\mathrm{C}_{10}, \mathrm{C}_{12}$, and $\mathrm{C}_{14}$ were recrystallized from acetone, and $\mathrm{C}_{16}$ from methanol/diethyl ether. $\mathrm{C}_{18}$ was purified by the precipitation of its methanol solution into

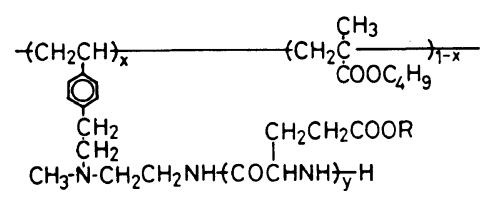

I $\quad\left(\mathrm{R}=\mathrm{CH}_{2} \mathrm{C}_{6} \mathrm{H}_{5}, \mathrm{H}\right)$ acetone. Phenyl-1,2-ethanediol was recrystallized from benzene. The other chemicals used were of reagent grade.

\section{Preparation of Polymer Membrane}

The membrane prepared by casting the chloroform solution of the graft copolymer $(\mathrm{I}, \mathrm{R}=$ $\mathrm{CH}_{2} \mathrm{C}_{6} \mathrm{H}_{5}$ ) was fixed vertically in the center of a diaphragm cell. In order to convert the benzyl ester group of the poly $(\gamma$-benzyl Lglutamate) to carboxylate group, hydrolysis of the membrane was performed by filling both sides of the cell with water-methanol-2propanol mixture $(1: 2: 2$, by volume) containing $0.5 \mathrm{wt} \% \mathrm{KOH}$ at $25^{\circ} \mathrm{C}$ for $16 \mathrm{~h}$. The debenzylation of the poly $(\gamma$-benzyl L-glutamate) branch could be performed almost perfectly. ${ }^{10}$ Thus, the membrane after the hydrolysis is regarded to be composed of PBMA-g-PLGA $(\mathrm{I}, \mathrm{R}=\mathrm{H})$.

\section{Permeation}

The membrane after the hydrolysis was treated with $0.1 \mathrm{M}$ aqueous $\mathrm{NaOH}, 0.1 \mathrm{M}$ aqueous $\mathrm{HCl}$, or $5 \times 10^{-3} \mathrm{M}$ solution of a surfactant by filling both sides of the cell for $40 \mathrm{~h}$. After removal of the solution, the membrane was washed with pure water several times and kept in pure water for about $1 \mathrm{~h}$. Then, $50 \mathrm{~cm}^{3}$ of aqueous solution of phenyl-1,2-ethanediol $(0.1 \mathrm{M})$ was introduced into one side of the cell and $50 \mathrm{~cm}^{3}$ of pure water into the other side. The solutions in both sides of the cell were stirred slowly at $30^{\circ} \mathrm{C}$. The extent of the permeation of phenyl-1,2-ethanediol was determined by UV measurement using a JASCO UVIDEC-1 recording spectrophotometer.

\section{Circular Dichroism (CD) Spectra ${ }^{9}$}

The thin film ( $c a .2 \mu \mathrm{m}$ in thickess) was attached to a quartz plate $(50 \mathrm{~mm} \times 9 \mathrm{~mm}$, $5 \mathrm{~mm}$ thick), and subjected to hydrolysis by the same procedure as that for the membrane used in permeation studies. The CD spectra of the film were measured by placing the quartz plate attaching the film in a quartz cell (path length, 
$10 \mathrm{~mm}$ ) filled with pure water, using a JASCO $\mathrm{J}-500 \mathrm{~A}$ spectropolarimeter.

\section{RESULTS AND DISCUSSION}

\section{Effect of Surfactants on the Membrane Treated with $\mathrm{NaOH}$}

Figure 1 shows the CD spectra of the film composed of PBMA- $g$-PLGA (I, R=H; $x=$ $0.032, y=27)$ treated with $0.1 \mathrm{M} \mathrm{NaOH}$ followed by a surfactant. Upon treatment with $\mathrm{NaOH}$, PLGA chains in the film assumed a random coil conformation as shown in No. 1 of Figure 1. After the treatment of this film with $5 \times 10^{-3} \mathrm{M}$ solution of $\mathrm{C}_{14}$, the $\mathrm{CD}$ spectra (No. 2) exhibited a negative curve centered at $223 \mathrm{~nm}$, which indicates the formation of right-handed $\alpha$-helix, in a similar manner to PLGA in acidic aqueous solution ${ }^{10}$ and in the film. ${ }^{11}$ This spectrum did not change even when the film was kept in pure water for 3 days, while completely reverted treatment with $\mathrm{NaOH}$. Almost the same CD spectra as No. 2 were also obtained in the treatment with $\mathrm{C}_{12}$ and $\mathrm{C}_{10}$. On the other hand, $\mathrm{C}_{16}$ had no effect on the CD spectrum as shown in No. 3, which demonstrates that PLGA chains in the film treated with $\mathrm{C}_{16}$ are still in the random coil conformation. In the treatment with $\mathrm{C}_{18}$ as well, no change in the $\mathrm{CD}$ spectrum was observed.

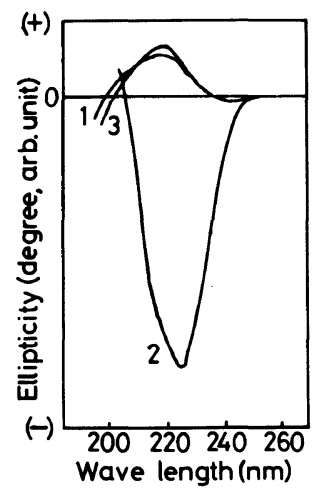

Figure 1. $\mathrm{CD}$ spectra of a film pretreated with $0.1 \mathrm{M}$ aqueous $\mathrm{NaOH}(1)$, then treated with $5 \times 10^{-3} \mathrm{M}$ solution of: $\mathrm{C}_{14}(2) ; \mathrm{C}_{16}$ (3).
Using these surfactants which exhibited characteristic effects on the conformation of PLGA, the effect on the permeability of phenyl-1,2-ethanediol was investigated for the membrane treated with $\mathrm{NaOH}$. First, the permeation experiment was carried out in pure water for the membrane treated with $0.1 \mathrm{M}$ $\mathrm{NaOH}$, to give the results shown in No. 1 of Figure 2. After this experiment, the same membrane was treated with $5 \times 10^{-3}$ solution of $\mathrm{C}_{10}$ for $40 \mathrm{~h}$, and the permeation experiment was carried out in pure water. As shown in No. 2 , a decrease in permeability was observed. Alternating treatment with $\mathrm{NaOH}$ and a surfactant, and the permeation experiment in pure water were continued for the same membrane. Upon the treatment with $\mathrm{NaOH}$, the permeability suppressed by a surfactant almost completely reverted to its initial value (No. 1) for the membrane treated with $\mathrm{C}_{10}, \mathrm{C}_{12}$, and $\mathrm{C}_{14}$. On the other hand, for the membrane treated with $\mathrm{C}_{16}$ and $\mathrm{C}_{18}$, the permeability did not reverted by treatment with $\mathrm{NaOH}$. However, after the membrane was once treated with $0.1 \mathrm{M} \mathrm{HCl}$, the permeability reverted by treatment with $\mathrm{NaOH}$. As clearly demonstrated in Figure 2, all the surfactants examined had the ability to diminish the perme-

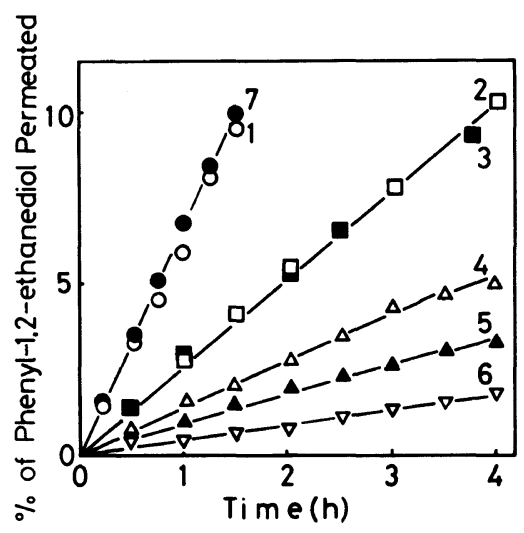

Figure 2. Permeation profiles of phenyl-1,2-ethanediol across the membrane pretreated with $0.1 \mathrm{M}$ aqueous $\mathrm{NaOH}(1(\mathrm{O}), 7(\bigcirc))$, then treated with surfactants $\left(5 \times 10^{-3} \mathrm{M}\right) ; 2(\square), \mathrm{C}_{18} ; 3(\square), \mathrm{C}_{16} ; 4(\triangle), \mathrm{C}_{14} ; 5(\Delta)$, $\mathrm{C}_{12} ; 6(\nabla), \mathrm{C}_{10}$. Numbers represent the order of the permeation experiments. 
ability of phenyl-1,2-ethanediol, and the effect on the permeability was in the order: $\mathrm{C}_{10}>\mathrm{C}_{12}>\mathrm{C}_{14}>\mathrm{C}_{16} \simeq \mathrm{C}_{18}$.

In the aqueous solution of the homopolymer of PLGA at neutral pH, coil-to-helix transition of PLGA observed in the presence of decylammonium chloride and $\mathrm{C}_{12}$ has been considered due to hydrophobic interaction among the surfactant ions bound to PLGA. ${ }^{3,4}$ On the other hand, $\mathrm{C}_{16}$ brings about a conformational transition of PLGA at $\mathrm{pH} 4.5$ from $\alpha$-helix to random coil, ${ }^{4}$ but the mechanism has not been clearly explained.

For the PBMA-g-PLGA membrane, as described above, $\mathrm{C}_{10}, \mathrm{C}_{12}$, and $\mathrm{C}_{14}$ were found to induce the coil-to-helix transition of PLGA chains in the membrane treated with $\mathrm{NaOH}$, while $\mathrm{C}_{16}$ and $\mathrm{C}_{18}$ had no effect on the random coil conformation of PLGA chains. On the other hand, all these surfactants brought about a decrease in the permeability of phenyl1,2-ethanediol. In the membrane treated with the surfactants with a long alkyl chain, the hydrophobicity of the permeating pathway is considered to increase so that it becomes difficult for hydrophilic phenyl-1,2-ethanediol to permeate across the membrane. Thus, the decrease in the permeability brought about by the cationic surfactants is considered, at least partly, due to the increase in the hydrophobicity of the permeating pathway. However,

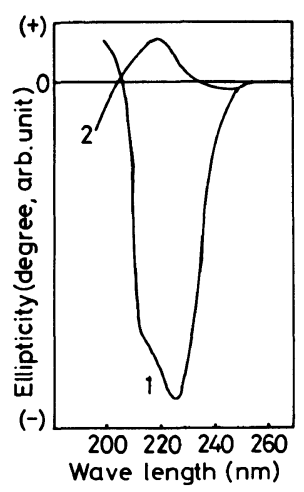

Figure 3. $\mathrm{CD}$ spectra of a film pretreated with $0.1 \mathrm{M}$ aqueous $\mathrm{HCl}(1)$, then treated with $5 \times 10^{-3} \mathrm{M}$ solution of $\mathrm{C}_{16}$ (2).
$\mathrm{C}_{10}, \mathrm{C}_{12}$, and $\mathrm{C}_{14}$ with a shorter alkyl chain are more effective for the decrease in the permeability than that for $\mathrm{C}_{16}$ and $\mathrm{C}_{18}$. Since $\mathrm{C}_{10}$, $\mathrm{C}_{12}$, and $\mathrm{C}_{14}$ induce the coil-to-helix transition of PLGA, the conformational transition of PLGA from random coil to $\alpha$-helix is considered also to contribute to the decrease in the permeability of phenyl-1,2-ethanediol, for the membrane treated with $\mathrm{C}_{10}, \mathrm{C}_{12}$, and $\mathrm{C}_{14}$. The rigid $\alpha$-helical form of PLGA is considered to bring about the tight structure of the permeating pathway composed of PLGA assembly so that the permeability diminishes.

\section{Effects of Surfactants on the Membrane Treat- ed with $\mathrm{HCl}$}

Upon treatment of the film composed of PBMA- $g$-PLGA (I, R=H; $x=0.035, y=21)$ with $0.1 \mathrm{M} \mathrm{HCl}$, the $\mathrm{CD}$ spectrum exhibited a negative curve centered at $223 \mathrm{~nm}$ which indicates the formation of right-handed $\alpha$-helix of the PLGA chains, as shown in No. 1 of Figure 3. This spectrum did not change by treatment with $\mathrm{C}_{10}, \mathrm{C}_{12}$, and $\mathrm{C}_{14}$. On the contrary, the $\mathrm{CD}$ spectrum after treatment with $5 \times 10^{-3} \mathrm{M}$ solution of $\mathrm{C}_{16}$ (No. 2) showed a pronounced decrease in intensity at $223 \mathrm{~nm}$, which indicates the destruction of the $\alpha$-helical form of PLGA in the film. Almost the

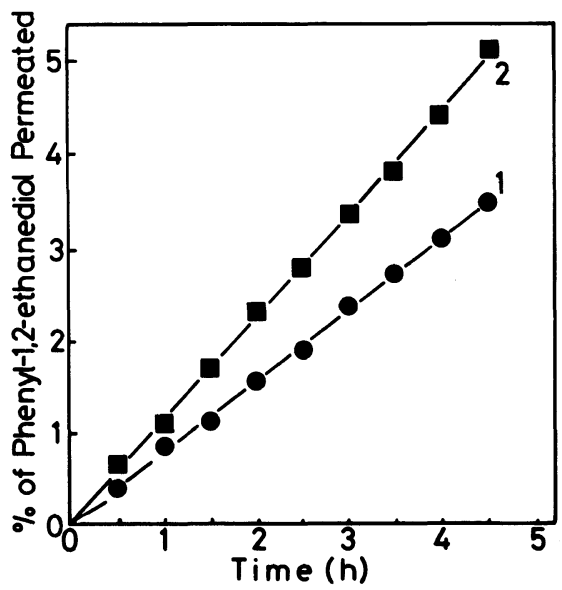

Figure 4. Permeation profiles of phenyl-1,2-ethanediol across the membrane treated with $0.1 \mathrm{M}$ aqueous $\mathrm{HCl}(1$, ) followed by $5 \times 10^{-3} \mathrm{M}$ solution of $\mathrm{C}_{16}(2, \square)$. 
same CD spectrum was observed for treatment with $\mathrm{C}_{18}$, and the changes in $\mathrm{CD}$ spectra reversed upon alternating treatment with $\mathrm{HCl}$ and $\mathrm{C}_{16}$ or $\mathrm{C}_{18}$.

Figure 4 illustrates the effect of $\mathrm{C}_{16}$ on the permeability of phenyl-1,2-ethanediol across the membrane treated with $0.1 \mathrm{M} \mathrm{HCl}$. As shown in Figure 4, the permeability of phenyl1,2-ethanediol was enhanced by treatment with $\mathrm{C}_{16}$. Increase in permeability was also observed for treatment with $\mathrm{C}_{18}$. It should be noted that, even in the treatment by $\mathrm{C}_{16}$ or $\mathrm{C}_{18}$ with a long alkyl chain, the membrane exhibited a higher permeability. Since $\mathrm{C}_{16}$ and $\mathrm{C}_{18}$ has the ability to induce the helix-to-coil transition of PLGA, the increase in permeability is considered due to the conformational change of PLGA from $\alpha$-helix to random coil by which the permeability pathway becomes loose.

The membrane treated with $\mathrm{C}_{14}$ showed a lower permeability of phenyl-1,2-ethanediol. $\mathrm{C}_{10}$ and $\mathrm{C}_{12}$ were also found to have the ability to diminish the permeability. Since $C_{10}, C_{12}$, and $\mathrm{C}_{14}$ had no effect on the $\alpha$-helical conformation of PLGA, the decrease in permeability by treatment with $\mathrm{C}_{14}$ is considered to be induced by increase in the hydrophobicity of the permeating pathway, by a similar effect to that of the surfactants on the permeability across the membrane treated with $\mathrm{NaOH}$.

For the membrane pretreated with $\mathrm{HCl}$, the permeability thus enhanced or suppressed by $\mathrm{C}_{16}$ or $\mathrm{C}_{14}$ did not revert to the initial state even by subsequent treatment of the membrane with $\mathrm{HCl}$.

\section{CONCLUSIONS}

In our previous studies, ${ }^{8}$ cationic surfactants with a dodecyl group in common such as dodecylammonium, dodecyldimethylammonium, and dodecyltrimethylammonium chlorides had the ability to diminish the permeability of phenyl-1,2-ethanediol across the membrane composed of poly(butyl methacrylate)-poly(L-glutamic acid) graft copolymer pretreated with $\mathrm{NaOH}$. The decrease in permeability was discussed in terms of the conformational transition of PLGA from random coil to $\alpha$-helix as observed by the CD spectra.

In further extensive studies described here on the effects of cationic surfactants with an alkyl group of different chain lengths, examples were found where decrease in permeability was observed regardless of change in the conformation of PLGA in the membrane. From these results, the effects of cationic surfactants with a long alkyl chain examined here on the permeability are considered due to increase in the hydrophobicity of the permeating pathway composed of PLGA chains, and/or their conformational transition in the membrane.

\section{REFERENCES}

1. P. K. Sarkar and P. Doty, Proc. Natl. Acad. Sci. U.S.A., 55, 981 (1966).

2. For examples, (a) I. Satake and J. T. Yang, Biochem. Biophys. Res. Commun., 54, 930 (1973).

(b) G. D. Fasman, C. Lindblow and E. Bodenheimer, Biochemistry, 3, 155 (1964).

(c) H. Maeda, H. Kato, and S. Ikeda, Biopolymers, 23, 1333 (1984).

3. I. Satake, T. Gondo, and H. Kimizuka, Bull. Chem. Soc. Jpn., 52, 361 (1979).

4. W. L. Mattice, R. W. McCord, and P. M. Shippey, Biopolymers, 18, 723 (1979).

5. M. Maeda, M. Kimura, Y. Hareyama, and S. Inoue, J. Am. Chem. Soc., 106, 250 (1984).

6. S. Higuchi, T. Mozawa, M. Maeda, and S. Inoue, Macromolecules, 19, 2263 (1986).

7. D-w. Chung, M. Maeda, and S. Inoue, Makromol. Chem. (in press).

8. D-w. Chung, K. Kurosawa, M. Maeda, and S. Inoue, Makromol. Chem. (in press).

9. D-w. Chung, S. Higuchi, M. Maeda, and S. Inoue, $J$. Am. Chem. Soc., 108, 5823 (1986).

10. G. Holzwarth and P. Doty, J. Am. Chem. Soc., 87, 218 (1965).

11. G. D. Fasman, H. Hoving, and S. N. Timasheff, Biochemistry, 9, 3316 (1970). 